\title{
A Novel Approach to the Assessment of Afferent Pupillary Defects
}

\author{
M. T. BENSON, M. E. NELSON, I. A. CUNLIFFE, I. G. RENNIE \\ Sheffield
}

\begin{abstract}
Summary
The pupil response to a flashing light stimulus was observed for a group of 26 healthy volunteer controls, and 15 patients with relative afferent pupillary defects (RAPDs). For the control group, the mean interval between flashes which would just produce a perceptible pupil response was 295 milliseconds $(\mathrm{ms})$. The mean difference between right and left eyes was $8.84 \mathrm{~ms}$. The mean difference between normal and abnormal eyes of the APD group was $78.6 \mathrm{~ms}$. The difference between these results and those of the control group are highly significant statistically $(p<0.001)$, and we conclude that this test may be of use in the assessment of defects of the afferent light pathways.
\end{abstract}

The relative afferent pupillary defect (RAPD) is an extremely useful clinical sign, giving information in a wide range of conditions which involve the pre-geniculate visual pathways. ${ }^{1-13}$ Assessment of a RAPD may aid diagnosis and influence management.

In order to chart the course of a disease, and to enable a comparison between the affected eyes of different patients, it is useful to measure the amount of RAPD present. Some clinicians assign a numerical grade to the RAPD. Such rough rating systems are highly subjective and prone to error. ${ }^{14}$ The measurement of RAPDs using neutral density (ND) filters has been strongly advocated by some authors. ${ }^{14,15,16}$ However, there are technical problems associated with this method. The quantification of RAPDs with ND filters is influenced by the test light used, ${ }^{17}$ and causes asymmetric bleaching of the retinas. ${ }^{14}$ The 'blanket' reduction in afferent input produced by ND filters is not necessarily the same afferent defect as the one to be matched.

The pupil cycle time has been suggested as a useful clinical test for assessment of optic nerve function. ${ }^{18,19,20}$ This test utilises efferent and afferent pathways for the eye under observation. Whereas the RAPD is a relative sign, which disappears if the other eye develops a matching dysfunction, the pupil cycle time is objective for each eye individually and can be used even in monocular patients. However, the pupil cycle time is a difficult and time-consuming test to perform. Moreover, it is a relatively insensitive indicator of optic nerve disease. ${ }^{3}$

It was our aim to produce a test of afferent visual pathway function which was easy and quick to perform, and which would allow the measurement of the RAPD directly. Pupillographic studies of afferent pupillary defects show that when the affected eye is stimulated the pupillary contraction has a longer latent period and a smaller amplitude than when the unaffected eye is stimulated. ${ }^{9}$ Since the abnormal response is of greater latency and reduced amplitude, we reasoned that the observed pupillary response to a flashing light would be diminished, and that disappearance of visible response with increasing flash fre-

From: Department of Ophthalmology, University of Sheffield; and Royal Hallamshire Hospital, Sheffield.

Correspondence to: Mr M. T. Benson, Department of Ophthalmology, Royal Hallamshire Hospital, Sheffield S10 2JF. 
Table I. Age, sex and pupil response measurements in milliseconds of control population

\begin{tabular}{rccccc}
\hline No. & Age & Sex & Right & Left & Difference \\
\hline 1 & 22 & F & 240 & 240 & 0 \\
2 & 23 & F & 250 & 240 & 10 \\
3 & 32 & M & 290 & 310 & 20 \\
4 & 21 & F & 240 & 260 & 20 \\
5 & 20 & F & 250 & 260 & 10 \\
6 & 30 & M & 320 & 320 & 0 \\
7 & 25 & M & 330 & 340 & 10 \\
8 & 45 & F & 220 & 240 & 20 \\
9 & 42 & M & 310 & 320 & 10 \\
10 & 37 & F & 320 & 360 & 40 \\
11 & 30 & M & 320 & 330 & 10 \\
12 & 43 & F & 320 & 330 & 10 \\
13 & 29 & F & 320 & 310 & 10 \\
14 & 58 & F & 350 & 350 & 0 \\
15 & 38 & F & 330 & 330 & 0 \\
16 & 24 & F & 260 & 270 & 10 \\
17 & 26 & M & 350 & 350 & 0 \\
18 & 21 & F & 320 & 320 & 0 \\
19 & 24 & F & 290 & 270 & 20 \\
20 & 23 & F & 260 & 250 & 10 \\
21 & 22 & F & 270 & 260 & 10 \\
22 & 23 & F & 250 & 240 & 10 \\
23 & 75 & M & 330 & 330 & 0 \\
24 & 70 & M & 320 & 320 & 0 \\
25 & 76 & F & 300 & 300 & 0 \\
26 & 78 & M & 290 & 290 & 0 \\
\hline
\end{tabular}

quency could be used as an end-point for assessment of RAPDs.

\section{Method}

Subjects were enrolled for the study from the general ophthalmic outpatient clinic. Assessment of RAPDs was carried out by noting any asymmetry of pupillary escape during the swinging flashlight test, using a bright light in a dim room with the patient fixating a distant target. ${ }^{1,5,14,21-24}$ The control population comprised healthy volunteers with no history of ocular disease. For all subjects a full medical, drug and ophthalmic history was obtained. Visual acuity, refractive error, and pupil size were recorded.

Pupil responses were stimulated with flashes of white light from a stroboscope con- taining a xenon flash-tube, which subjects were asked to view through an eyepiece. The unstimulated eye fixated a distant target in a mirror. Flashes were of 7.5 microseconds duration, and since, at the outset, it was not known if flash intensity would be a significant factor, two intensities were used, namely 42 and $670 \mathrm{~cd} / \mathrm{s} / \mathrm{m}^{2}$. The mean background illumination was $15 \mathrm{~cd} / \mathrm{m}^{2}$. The response of the unstimulated eye was observed. The interval between flashes of light was initially 500 milliseconds. This interval was then decreased in 100 millisecond decrements until the pupil response of the unstimulated eye was no longer perceptible. The interval between flashes at which this occurred was recorded and the test was then performed on the other eye. For each eye the test was then repeated starting at the first end-point and increasing the interval between flashes by 10 millisecond increments until a pupil response was just observed. The interval between flashes at which this occurred was recorded as the final end-point. The test was carried out for each intensity of stimulating light, and the observer was masked with respect to any pupillary abnormality of the subject, and to the flash frequency being used at any particular time.

\section{Results}

It was found that the results for the two different flash intensities were almost identical, and therefore only one set of results (those using the $670 \mathrm{~cd} / \mathrm{s} / \mathrm{m}^{2}$ flash) are presented here.

Twenty-six healthy volunteer subjects (Table I) were recruited for the study. The mean age of this group was 33.8 years (range 20-76) (Table II). For control subjects the mean interval between flashes at which a pupil response was just perceptible was 295 milliseconds (321 for males and 283 for females) (Table III). The mean difference between the end-point for right and left eyes was 8.84 milliseconds (5.5 for males and 10.5 for females) (Table IV). There was no positive correlation

Table II. Age distribution of controls and patients with afferent pupillary defects. $M=$ male, $F=$ female

\begin{tabular}{lcccc}
\hline & \multicolumn{3}{c}{ Controls } & RAPD group \\
\hline Mean age & 33.8 & {$[\mathrm{M} 36.6, \mathrm{~F} 32.3]$} & 75.1 & {$[\mathrm{M} 74.3, \mathrm{~F} 76.8]$} \\
Range & $20-76$ & {$[\mathrm{M} 25-68, \mathrm{~F} 20-76]$} & $61-86$ & {$[\mathrm{M} 61-86, \mathrm{~F} 70-82]$} \\
$\mathrm{n}$ & 26 & {$[\mathrm{M} 9, \mathrm{~F} 17]$} & 15 & {$[\mathrm{M} 10, \mathrm{~F} 5]$} \\
\hline
\end{tabular}


Table III. Pupil responses, in milliseconds of interval, of control population. $S D=$ standard deviation

\begin{tabular}{lcc}
\hline & Mean (SD) for all & Means (SDs) for sexes \\
\hline Right & $294(37.5)$ & {$[$ M317 (19.2), F281 (39.2)] } \\
Left & $295(38.0)$ & {$[$ M323 (17.3), F284 (41.5)] } \\
Both & $295(38.2)$ & {$[$ M321 (18.0), F283 (39.8)] } \\
\hline
\end{tabular}

between the difference in end-point between the two eyes of this group, and the age of the subjects.

Fifteen patients with RAPDS (Table V) were recruited for the study. The mean age of these patients was 75.1 years (range 61-86) (Table II). For this group the mean difference in end-point between the normal and abnormal eyes was 78.6 milliseconds (Table VI). The difference between the results for the control and the RAPD populations is highly significant statistically $(\mathrm{p}<0.001 \mathrm{using}$ a one-sided Mann-Whitney test).

\section{Discussion}

Since it indicates an imbalance in the pregeniculate light pathways, the RAPD may provide useful clinical information in a wide range of conditions, including optic neuritis, $, 1,2$ ischaemic or compressive optic neuropathy, ${ }^{1,3}$ occlusion of the central retinal artery or vein, ${ }^{1}$ asymmetrical glaucomatous damage, ${ }^{4-8}$ amblyopia, ${ }^{9,10,11}$ contralateral to an optic tract lesion, ${ }^{12}$ large macular lesions, ${ }^{5}$ retinal detachment, ${ }^{1,5,13}$ and extensive organic disease of the retina. ${ }^{1}$

In patients with unilateral optic neuropathy the RAPD is more sensitive than the visual evoked potential (VEP) and the pupil cycle time as an indicator of disease. ${ }^{3}$ However, the RAPD is of use only when the disease is unilateral, and bilateral disease may be missed, i.e. it does not replace the VEP in detecting past optic neuritis.

The numerical grading of RAPDs, e.g. from $1+$ to $4+$, is subject to error, e.g. because of pupil size (small pupils make the RAPD seem less), ${ }^{14}$ and because it is highly subjective.

The measurement of RAPDs with neutral density filters has been recommended. ${ }^{14-16}$ Using this technique the smallest defect that can be measured with confidence is $0.3 \mathrm{log}$ units. ${ }^{14}$ This method is not free from technical problems. Above $1.2 \log$ units, the filter is so dense that it becomes necessary to look around it to see the pupil move. ${ }^{14}$ The quantification of RAPDs with ND filters is influenced by the test light used, ${ }^{17}$ and causes asymmetric bleaching of the retinas. ${ }^{14}$ Also, the ND filters cause a reduction in the incident light across the entire retina, which is not necessarily the same afferent defect as the one to be matched. One disadvantage of the RAPD is that it is a relative sign, and therefore disappears if the other eye develops a matching dysfunction.

In patients who are strongly suspected of having an RAPD but in whom pupillary testing is not possible, brightness comparison testing can be helpful, and in some subgroups it can reliably predict the presence or absence of an RAPD, but it is very subjective. ${ }^{25}$

The pupil cycle time may be used to assess optic nerve function. ${ }^{18-20} \mathrm{~A}$ small beam of light focussed at the pupillary margin induces regular, persistent oscillations of the pupil. One hundred cycles may be timed with a stopwatch to the nearest $0.1 \mathrm{sec}$, and the average time in milliseconds for a single cycle is then termed the pupil cycle time. ${ }^{18-20}$ The pupil cycle time is objective for each eye individually. However, it is a difficult test to perform, and can be time-consuming because of blinking and losses of fixation, and it is a relatively insensitive indicator of optic nerve disease. ${ }^{3}$

Our test demonstrated remarkable consistency between the end-points for the two eyes of the control subjects, and between different subjects (Tables I and III). It should be emphasised that the observer was masked with regard to the flash frequency being used. The end-points for individual eyes show a bimodal distribution, the cause for which is not clear, but seems to be related to sex, insofar as all male controls fall into the less rapid response group, whereas the females are predominantly in the more rapid group (Tables I

Table IV. Mean difference in pupil response between individuals' eyes, in milliseconds of interval, for controls

Mean Difference

\begin{tabular}{lc}
\hline Male & 5.5 \\
Female & 10.5 \\
All & 8.84 \\
\hline
\end{tabular}


Table V. Age, sex, diagnosis and pupil measurements in milliseconds of interval of RAPD group. AMD = agerelated macular degeneration; $P O A G=$ primary open-angle glaucoma; $C R V O=$ central retinal vein occlusion; $C R A O=$ central retinal artery occlusion; $A I O N=$ anterior ischaemic optic neuropathy; $O A=$ optic atrophy. Diagnosis in brackets $=$ concurrent condition $(*=$ condition in other eye $)$

\begin{tabular}{|c|c|c|c|c|c|c|}
\hline No. & Age & Sex & Diagnosis & $\begin{array}{c}\text { Affected } \\
\text { Eye }\end{array}$ & $\begin{array}{c}\text { Unaffected } \\
\text { Eye }\end{array}$ & Difference \\
\hline 1 & 81 & $\mathbf{M}$ & AMD & 310 & 280 & 30 \\
\hline 2 & 78 & $\mathrm{~F}$ & POAG & 290 & 280 & 10 \\
\hline 3 & 82 & $\mathrm{~F}$ & CRVO & 520 & 420 & 100 \\
\hline 4 & 86 & M & CRVO & 480 & 440 & 40 \\
\hline 5 & 74 & $\mathrm{~F}$ & CRAO (BRVO)* & 580 & 420 & 160 \\
\hline 6 & 76 & $\mathbf{M}$ & CRVO (POAG) & 550 & 380 & 170 \\
\hline 7 & 79 & $\mathbf{M}$ & CRVO & 420 & 370 & 50 \\
\hline 8 & 70 & $\mathrm{~F}$ & AION & 440 & 360 & 80 \\
\hline 9 & 69 & $\mathbf{M}$ & AION (POAG) & 600 & 330 & 270 \\
\hline 10 & 81 & $\mathbf{M}$ & CRVO & 340 & 300 & 40 \\
\hline 11 & 80 & $\mathrm{~F}$ & CRVO (POAG) & 370 & 330 & 40 \\
\hline 12 & 70 & M & $\mathrm{OA}$ & 370 & 330 & 40 \\
\hline 13 & 61 & $\mathbf{M}$ & CRVO & 340 & 300 & 40 \\
\hline 14 & 67 & $\mathbf{M}$ & CRVO & 360 & 320 & 40 \\
\hline 15 & 66 & $\mathbf{M}$ & CRVO (POAG) & 360 & 290 & 70 \\
\hline
\end{tabular}

and III). This is consistent with the finding that females tend to have a shorter latency on testing of the visual evoked potential than males. There was no significant difference between the two flash intensities used in this study with regard to eliciting these end-points.

Although the mean age of our control subjects was less than that of the RAPD population, it was evident from our control population that there was no positive correlation between subject age and difference in end-point between the two eyes.

The difference between normal and abnormal eyes of those subjects with RAPDs was highly significant statistically (Table VI). It is possible that the end-point for this test is determined in part by the observer's threshold of observation, just as it is when ND filters are used, but as long as the same observer defines the end-point for the two eyes of a patient this should not matter, as the test is a measure of the difference between the two

Table VI. Mean difference in pupil response between 'normal' and 'abnormal' eyes, in milliseconds of interval, for patients with RAPD

\begin{tabular}{lc}
\hline & Mean Difference \\
\hline Normal & 343 \\
Abnormal & 422 \\
Difference & 78.6 \\
\hline
\end{tabular}

eyes. Provided the same stimulus is used for both eyes of a patient, the value for the pupil response difference could be compared to the values for other patients. In conclusion, this test appears to be of value in measuring the pupil response directly, giving remarkably consistent and highly significant results with a masked observer. Although it requires much further evaluation, including comparison with established techniques for pupil assessment, it is hoped that this test may be of use in the assessment of defects of the afferent light pathways.

\section{References}

${ }^{1}$ Levatin P: Pupillary escape in disease of the retina or optic nerve. Arch Ophthalmol 1959, 62: 768-79.

${ }^{2}$ Stanley JA and Baise GR: The swinging flashlight test to detect minimal optic neuropathy. Arch Ophthalmol 1968, 80: 769-71.

${ }^{3}$ Cox TA, Thompson HS, Hayreh SS, Synder JE: Visual evoked potential and pupillary signs. Arch Ophthalmol 1982, 100: 1603-7.

${ }^{4}$ Kabak MB, Burde RM, Becker B: Relative afferent pupillary defect in glaucoma. Am J Ophthalmol 1976, 81: 462-8.

${ }^{5}$ Thompson HS: Pupillary signs in the diagnosis of optic nerve disease. Trans Ophthalmol Soc UK 1976, 96: 377-81.

${ }^{6}$ Quigley HA, Addicks EM, Green WR: Optic nerve damage in human glaucoma: III. Quantitative correlation of nerve fiber loss and visual field defect in glaucoma, ischemic neuropathy, papilledema, and toxic neuropathy. Arch Ophthalmol 1982, 100: 135-46. 
${ }^{7}$ Kohn AN, Moss AP, Podos SM: Relative afferent pupillary defects in glaucoma without characteristic field loss. Arch Ophthalmol 1979, 77: 294-6.

${ }^{8}$ Johnson LN, Hill RA, Bartholomew MJ: Correlation of afferent pupillary defect with visual field loss on automated perimetry. Ophthalmology 1988, 95: 1649-55.

${ }^{9}$ Thompson HS: Afferent pupillary defects. Pupillary findings associated with defects of the afferent arm of the pupillary light reflex arc. $A m J O p h$ thalmol 1966, 62: 860-73.

${ }^{10}$ Portnoy JZ, Thompson HS, Lennarson L, Corbett JJ: Pupillary defects in amblyopia. Am J Ophthalmol 1983, 96: 609-14.

${ }^{11}$ Greenwald MJ and Folk ER: Afferent pupillary defects in amblyopia. J Pediatr Ophthalmol Strabismus 1983, 20: 63-7.

${ }^{12}$ O'Connor PS, Kasdon D, Tredici TJ, Ivan DJ: The Marcus Gunn pupil in experimental tract lesions. Ophthalmology 1982, 89: 160-4.

${ }^{13}$ Bovino JA and Burton TC: Measurement of the relative afferent pupillary defect in retinal detachment. Am J Ophthalmol 1980, 90: 19-21.

${ }^{14}$ Thompson HS, Corbett JJ, Cox TA: How to measure the relative afferent pupillary defect. Surv Ophthalmol 1981, 26: 39-42.

${ }^{15}$ Thompson HS: Putting a number on the relative afferent pupillary defect. In Thomson HS (ed): Topics in Neuro-Ophthalmology, Baltimore, Williams \& Wilkins, 1979, 157-8.
${ }^{16}$ Fineberg E, Thompson HS: Quantitation of the afferent pupillary defect. In: Smith JL (ed) Neuro-ophthalmology focus 1980, New York, Masson publishing, 1980: 25-9.

${ }^{17}$ Browning DJ and Tiedeman JS: The test light affects quantitation of the afferent pupillary defect. $O p h$ thalmol 1987, 94: 53-5.

${ }^{18}$ Miller SD and Thompson HS: Pupil cycle time in optic neuritis. Am J Ophthalmol 1978, 85: 635-42.

${ }^{19}$ Miller SD and Thompson HS: Edge-light pupil cycle time. Br J Ophthalmol 1978, 62: 495-500.

${ }^{20}$ Miller SD and Thompson HS: The pupil cycle time. In Thomson HS (ed): Topics in Neuro-Ophthalmology, Baltimore, Williams \& Wilkins, 1979, 159-63.

${ }^{21}$ Cox TA. Pupillography of a relative afferent pupillary defect. Am J Ophthalmol 1986, 101: 320-4.

${ }^{22}$ Lowenstein O and Friedman ED: Pupillographic studies. Arch Ophthalmol 1942, 27: 969-93.

${ }^{23}$ Smith SA and Smith SE: Contraction anisocoria: nasal versus temporal illumination. Br J Ophthalmol 1980, 64: 933-4.

${ }^{24}$ Cox TA: Pupillographic characteristics of simulated relative afferent pupillary defects. Invest Ophthalmol Vis Sci 1989, 30: 1127-31.

${ }^{25}$ Browning DJ and Buckley EG: Reliability of brightness comparison testing in predicting afferent pupillary defects. Arch Ophthalmol 1988, 106: 341-3. 